\title{
Combined Quartz Crystal Microbalance with Dissipation (QCM-D) and Generalized Ellipsometry (GE) to Characterize the Deposition of Titanium Dioxide Nanoparticles on Model Rough Surfaces
}

\author{
Negin Kananizadeh $^{1,3}$, Charles Rice ${ }^{2,3}$, Jaewoong Lee ${ }^{1,3,4}$, Keith B. \\ Rodenhausen $^{2,3,5}$, Derek Sekora ${ }^{2,3}$, Mathias Schubert ${ }^{2,3}$, Eva Schubert ${ }^{2,3}$, Shannon \\ Bartelt-Hunt ${ }^{1,3}$, and Yusong $\mathrm{Li}^{1,3 *}$ \\ ${ }^{1}$ Department of Civil Engineering, University of Nebraska-Lincoln, Lincoln, NE 68588 \\ ${ }^{2}$ Department of Electrical and Computer Engineering, University of Nebraska-Lincoln, Lincoln, \\ NE 68588 \\ ${ }^{3}$ Center for Nanohybrid Functional Materials, University of Nebraska-Lincoln, Lincoln, NE \\ 68588 \\ ${ }^{4}$ Department of Water Environmental Engineering Research, National Institute of Environmental \\ Research 22755, Republic of Korea \\ ${ }^{5}$ Biolin Scientific, Inc., Paramus, NJ 07652
}

Submitted to

Journal of Hazardous Materials

November 30, 2015

Resubmitted: March 10, 2016

*Corresponding author. Tel.: (402)-472-5972; fax: (402)-472-8934; Email: yli7@ unl.edu 


\begin{abstract}
:
Measuring the interactions between engineered nanoparticles and natural substrates (e.g. soils and sediments) has been very challenging due to highly heterogeneous and rough natural surfaces. In this study, three-dimensional nanostructured slanted columnar thin films (SCTFs), with well-defined roughness height and spacing, have been used to mimic surface roughness. Interactions between titanium dioxide nanoparticles $\left(\mathrm{TiO}_{2} \mathrm{NP}\right)$, the most extensively manufactured engineered nanomaterials, and SCTF coated surfaces were measured using a quartz crystal microbalance with dissipation monitoring (QCM-D). In parallel, in-situ generalized ellipsometry (GE) was coupled with QCM-D to simultaneously measure the amount of $\mathrm{TiO}_{2} \mathrm{NP}$ deposited on the surface of SCTF. While GE is insensitive to effects of mechanical water entrapment variations in roughness spaces, we found that the viscoelastic model, a typical QCM-D model analysis approach, overestimates the mass of deposited $\mathrm{TiO}_{2} \mathrm{NP}$. This overestimation arises from overlaid frequency changes caused by particle deposition as well as additional water entrapment and partial water displacement upon nanoparticle adsorption. Here, we demonstrate a new approach to model QCM-D data, accounting for both viscoelastic effects and the effects of roughness-retained water. Finally, the porosity of attached $\mathrm{TiO}_{2} \mathrm{NP}$ layer was determined by coupling the areal mass density determined by QCM-D and independent GE measurements.
\end{abstract}

Keywords: Quartz Crystal Microbalance; Rough Surfaces; Engineered Nanoparticles; Nanoparticle Deposition; Generalized Ellipsometry. 


\section{1-Introduction}

In recent years, the deposition of nanoparticles onto various surfaces has been investigated using quartz crystal microbalance with dissipation (QCM-D) [1-17]. A QCM-D sensor surface maintains resonant mechanical oscillations which cause shear motions of sheet layers of liquid within which the sensor is embedded. Typically, bound to the circumference of the oscillating sensor, odd-numbered overtones of the fundamental resonance frequency are recorded. Small amounts of materials which adsorb onto the sensor surface increase the inertial mass per area of the sensor surface and shift the QCM-D sensor's fundamental and overtone frequencies. In the absence of adsorption, only viscosity affects the oscillations by energy dissipation if the surface is ideally smooth. QCM-D sensors coated with silica dioxide[1$3,6,7,10,14,16,17]$ were largely used to simulate the major silica oxide content in sandy aquifers, and aluminum dioxide or iron oxide-coated QCM-D sensors were sometimes [7,16] used to simulate the widely existing metal impurities in aquifer materials. All these studies were performed on idealized flat QCM-D surfaces. Natural sands and sediments, however, contain various degrees of non-uniformity at small scales, i.e., surface roughness. Although the significance of surface roughness on particle deposition has been demonstrated in various studies [18-24], the effects of surface roughness were not accounted for in current QCM-D studies of nanoparticle deposition.

Presence of surface roughness, however, would highly complicate the interpretation of QCM-D data. Surface roughness may couple or entrap small volumes of adjacent liquid and thereby increases the inertial mass load of the oscillating sensor surface. Furthermore, instead of laminar flow on a smooth surface, local non-laminar flow can be generated due to the liquid motion on rough surfaces [25]. Liquids can enter the pores and grooves of rough surfaces and 
result in additional load to the sensor thereby causing additional frequency shifts. The nonlaminar motion of liquid can contribute to additional viscous energy dissipation [25]. To our best knowledge, no previous work attempted to account for the complicated hydrodynamic conditions when interpreting QCM-D data for nanoparticle deposition onto rough surfaces.

The objective of this study is to measure the interaction of engineered nanoparticles with rough surfaces. Titanium dioxide nanoparticles $\left(\mathrm{TiO}_{2} \mathrm{NPs}\right)$, the most extensively manufactured engineered nanomaterials [26-28], were used as model particles. A combined QCM-D/GE approach, where the QCM-D was coupled with an in-situ generalized ellipsometry (GE), was used. Innovative three-dimensional nanostructured surfaces, referred to here as slanted columnar thin films (SCTFs), were coated on QCM-D sensor to generate surface roughness with controlled height and spacing. QCM-D and GE measurements were continuously conducted in parallel when $\mathrm{TiNO}_{2} \mathrm{NPs}$ were introduced into a windowed QCM-D liquid cell. A new model was developed to interpret the QCM-D measurements by incorporating both viscoelastic and surface roughness effects. Finally, the porosity of the attached $\mathrm{TiNO}_{2} \mathrm{NP}$ layer was determined by integrating independent GE measurements with the QCM-D model results. In this work we used simple water chemistry, i.e., de-ionized (DI) water at $\mathrm{pH} 7$, in order to focus on model development and method exploration. Metal oxides are known to greatly contribute to nanoparticle deposition $[7,16]$. Hence, alumina $\left(\mathrm{Al}_{2} \mathrm{O}_{3}\right)$ was used here as the model surfaceterminating material to simulate the omnipresence of metal oxide in the aquifer materials.

\section{2- Materials and Methods}

\section{2-1- $\mathrm{TiO}_{2} \mathrm{NP}$ Preparation and Characterization}


The stock solution of Titanium dioxide nanoparticle $\left(\mathrm{TiO}_{2} \mathrm{NP}\right)$ stabilized by polyacrylate sodium was purchased from Sciventions Company (Toronto, Canada). Stock $\mathrm{TiO}_{2} \mathrm{NP}$ solution $(1.5 \mathrm{mg} / \mathrm{mL})$ was diluted to $5 \mathrm{ppm}$ by adding nanopure water (18.2 M $\Omega$-cm, Barnstead Nanopure system) and sonicated in an ultrasonic water bath (FS 60, 100 W, 42 kHz, Fisher Scientific, Pittsburg, PA) for at least $1 \mathrm{hr}$. After sonication, the flask was cooled to $25^{\circ} \mathrm{C}$, and then $100 \mathrm{mM}$ $\mathrm{NaOH}$ or $\mathrm{HCl}$ was added to adjust $\mathrm{pH}$ to $7 \pm 0.1$. The number-weighted hydrodynamic diameter distribution and zeta potential of $\mathrm{TiO}_{2} \mathrm{NP}$ were measured using a 90Plus Particle Size Analyzer and a ZetaPALS zeta potential analyzer, respectively (Brookhaven Instruments Corporation, Holtsville, NY).

\section{2-2 Surface Preparation and Characterization}

For smooth flat surfaces, a $4 \mathrm{~nm} \mathrm{Al}_{2} \mathrm{O}_{3}$ film was deposited on Au-coated $5 \mathrm{MHz}$ AT-cut quartz crystal sensors (QSX 301, Biolin Scientific AB, Stockholm, Sweden) by atomic layer deposition (ALD) instrumentation (Fiji 200, Cambridge Nanotech). Thermal ALD alumina was deposited at $150^{\circ} \mathrm{C}$ for 45 cycles at 187 mTorr. Both ALD precursors, trimethylaluminum (TMA) and 18.2 M $\Omega$ nanopure water, were pulsed for $60 \mathrm{~ms}$ each, followed by a $20 \mathrm{~s}$ vacuum purge.

Si-SCTFs were fabricated via glancing angle deposition (GLAD) [29-31]. Briefly, Si chips (Kurt J. Lesker Co) were placed on a substrate holder in an ultra-high vacuum GLAD chamber. Si is evaporated at $1.8 \times 10^{-6}$ mbar and deposits onto an Au-coated $5 \mathrm{MHz}$ AT-cut quartz crystal (QSX 301) sensor which is placed at the substrate position. The incident flux of

particles at the substrate was at an angle of $85^{\circ}$ and which lead to a columnar growth at an angle of $65^{\circ}$ with respect to the substrate's normal. The deposition rate was maintained at $3 \AA / s$ and 
monitored by a deposition controller mounted normal to the flux direction. After 10 minutes of deposition, the thickness of the Si-SCTF was $100 \mathrm{~nm}$. The SCTF was stabilized by the deposition of a $4 \mathrm{~nm}$ thick conformal alumina film using the ALD technique.

Immediately following the fabrication of the SCTFs, rotation-scan characterization by GE was performed. An RC2-VI spectroscopic ellipsometer (J.A. Woollam Co., Inc.) with a spectral range of 193-1690 nm was used to characterize the SCTFs. GE measurements were conducted at different angle of incident of $45^{\circ}, 55^{\circ}, 65^{\circ}$, and $75^{\circ}$ with respect to the substrate normal while performing a full sample rotation from $0^{\circ}$ to $360^{\circ}$ in $6^{\circ}$ increments. Scanning electron microscopy (SEM) was conducted using FEI Nova NanoSEM450 field emission SEM.

\section{2-3- Combined Quartz Crystal Microbalance with Dissipation (QCM-D) and In-}

\section{Situ Generalized Ellipsometry (GE)}

The combinatorial QCM-D / GE system [31-37] consists of an E1 QCM-D (Biolin Scientific AB, Stockholm, Sweden) mounted to the sample stage of an M-2000 spectroscopic ellipsometer (J.A. Woollam, Co., Inc.). The alumina-coated Si-SCTF coated and flat aluminacoated QCM-D sensors were mounted subsequently within the QCM-D chamber, which contains windows at a $65^{\circ}$ angle of incidence with respect to the substrate normal for the probing light beam of an ellipsometry measurement $[34,36,38]$. The sensors were cleaned in the ALD chamber with oxygen and plasma on the same day of the $\mathrm{TiO}_{2} \mathrm{NP}$ deposition experiment. Prior to QCM-D measurements, GE was conducted on the alumina-coated Si-SCTF coated QCM-D sensor outside and inside of the liquid cell to find the properties of the SCTF and the angle of offset for probing light. Afterwards, nanopure water with the adjusted $\mathrm{pH}$ of $7 \pm 0.1$ was 
introduced into the liquid cell at a flow rate of $0.1 \mathrm{~mL} / \mathrm{min}$ to find the modified properties of SCTF in the liquid environment (Stage I). Then in situ GE and QCM-D measurements were set to start simultaneously. After achieving a baseline with a drift less than $0.25 \mathrm{~Hz} / \mathrm{hr}$ for all reported QCM-D overtones, $5 \mathrm{ppm} \mathrm{TiO}_{2} \mathrm{NP}$ with the adjusted $\mathrm{pH}$ of $7 \pm 0.1$ was introduced into the cell at the same flow rate of $0.1 \mathrm{~mL} / \mathrm{min}$ (Stage II). All measurements were performed twice with separate alumina-coated QCM-D sensors and alumina-coated Si-SCTF coated QCM-D sensors and $\mathrm{TiO}_{2} \mathrm{NP}$ solutions.

\section{3- Data Analysis Procedures}

\section{3-2- GE Model Analysis}

Generalized ellipsometry (GE) is a non-destructive and non-invasive optical technique that measures the change in polarization when light reflects off or transmits through a sample [39-41]. The polarization state of light are described by Stokes vector where real-valued Mueller matrix elements $\left(\mathrm{M}_{\mathrm{ij}}\right)$ link the Stokes vector before $\overrightarrow{S_{l}}$ and after $\overrightarrow{S_{o}}$ sample interaction [39]. $\mathrm{M}_{\mathrm{ij}}$ completely describe the optical response of an experimental system.

$$
\overrightarrow{\mathrm{S}_{\mathrm{o}}}=\mathbf{M} \cdot \overrightarrow{\mathrm{S}_{1}}
$$

GE used here, characterizes SCTFs properties including structural parameters (e.g., SCTF thickness, slanting angle, and slanting plane), depolarization factors, and the volume fraction of constituents (e.g., Si, ambient, and adsorbate). $\mathrm{M}_{\mathrm{ij}}$ spectra measured by RC2-VI or M-2000 spectroscopic ellipsometers were analyzed with CompleteEASE software (J. A. Wollam Co., Inc), which used a stratified optical model including an isotropic Au substrate, anisotropic SiSCTF, and ambient (Figure 1). The anisotropic layer of Si-SCTF was modeled by an anisotropic 
Bruggeman effective medium approximation (AB-EMA) which describes physical properties of SCTF including the SCTF height and volume fraction of constituents (e.g., Si, ambient, and adsorbate) [31,41]. Figure 1a depicts a schematics of the optical model, which includes the Au layer on top of the QCM-D sensor. The AB-EMA layer contains the optical constants of $\mathrm{Si}$ and void with the volume fraction parameters $\mathrm{f}_{\mathrm{Si}}$ and $\mathrm{f}_{\text {void, }}$, respectively. The conformal alumina layer was ignored in the calculation, because its effect onto the optical properties of the SCTF is negligible due to its small thickness (ca. $4 \mathrm{~nm}$ ). In order to find the varied parameters of ABEMA optical model, AB-EMA model approach was performed by best matching $\mathrm{M}_{\mathrm{ij}}$ spectra for each optical model iteration until the calculated and measured $\mathrm{M}_{\mathrm{ij}}$ match. When the QCM-D sensor surface was immersed in liquid, the effect of the ambient change from air to liquid was accounted for by replacing the optical constants of void $(\mathrm{N}=1)$ with the optical constants of the liquid and exchanging $\mathrm{f}_{\text {void }}$ with $\mathrm{f}_{\text {liquid. }}$. When $\mathrm{TiO}_{2} \mathrm{NP}$ deposit on the surface of SCTF (Figure 1b), the volume fraction of $\mathrm{TiO}_{2} \mathrm{NP}\left(\mathrm{f}_{\mathrm{TiO}_{2}}\right)$ was added to the AB-EMA layer as the inclusion to the fractional constituents of ambient, reducing $\mathrm{f}_{\text {liquid }}$ accordingly. The AB-EMA is derived under the assumption that all participating electromagnetic field components are coherent. Hence the AB-EMA represents a perfectly homogenized layer of material [41]. During this process, the thickness of $\mathrm{AB}$-EMA layer was constant and $\mathrm{TiO}_{2} \mathrm{NP}$ attachment was the only factor changing the $\mathrm{M}_{\mathrm{ij}}$ spectra. Therefore, the structural parameters (e.g., SCTF thickness, slanting angle, and slanting plane), as well as depolarization factors for SCTF with $\mathrm{TiO}_{2} \mathrm{NP}$ attached, were remained same as those of SCTF in water (Table 1). The change in $\mathrm{M}_{\mathrm{ij}}$ elements was modeled by finding the best-matching calculated data for $\mathrm{f}_{\mathrm{TiO}_{2}}$. Detailed explanation of the theory, assumptions, and model can be found in previous publications [35,41,42]. 


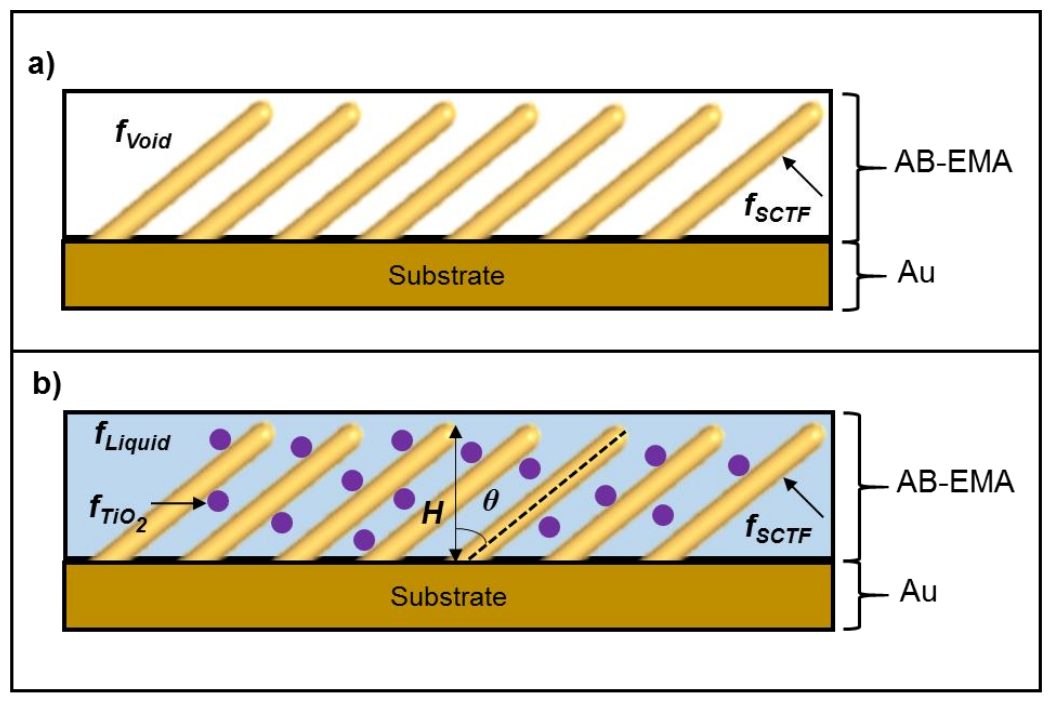

Figure 1: Schematic presentation of the optical models used in GE analysis of experimental data from a) SCTF coated Au QCM-D sensor in Air, and b) during $\mathrm{TiO}_{2} \mathrm{NP}$ adsorption in liquid ambient $\left(\mathrm{f}_{\mathrm{void}}=\mathrm{f}_{\text {liquid }}+\mathrm{f}_{\mathrm{TiO}_{2}}\right)$.

\section{3-2- QCM-D Model Analysis}

The measurement principle of the QCM is based on the inverse piezoelectric effect where an alternating applied voltage between metallic contacts on the top and bottom of an AT-cut quartz disc generates an oscillatory motion [43]. QCM measures shifts of the resonance frequency and its odd-numbered harmonic overtones $\Delta \mathrm{f}_{\mathrm{n}}$, which indicate the attachment or detachment of material to the surface or alternatively changes of the density and viscosity of the bulk ambient. For QCM-D measurements, the alternating voltage is periodically turned off, allowing the oscillation amplitude to decay [42]. The time-dependent amplitude loss behavior of the resonance frequency and its harmonic overtones are recorded as dissipation parameters $D_{n}$. Dissipation shifts $\Delta \mathrm{D}_{\mathrm{n}}$ indicate changes of the surface's viscoelasticity, as softer or ambientswollen layers tend to dampen the decaying oscillation faster. 
When a laterally homogeneous thin film is attached rigidly to the sensor (e.g., thin surfactant, polymer, or protein layers $[31,35,44])$, mass uptake can be quantified from $\Delta \mathrm{f}_{\mathrm{n}} / \mathrm{n}$ alone via the Sauerbrey equation [43].

$$
\frac{\Delta f_{n}}{n}=\frac{-2 f_{F}^{2} m_{f_{Q C M_{D}}}}{\sqrt{\rho_{q} \mu_{q}}}
$$

where $\mathrm{n}$ is the odd harmonic overtone number; $\mathrm{f}_{\mathrm{F}}$ is the fundamental resonance frequency (here 5 $\mathrm{MHz}) ; \mathrm{m}_{\mathrm{fQCM}-\mathrm{D}}$ is the areal mass density parameter of adsorbate $\left[\mathrm{ng} / \mathrm{cm}^{2}\right]$; and $\rho_{\mathrm{q}}\left(2.643 \times 10^{9}\right.$ $\left.\mathrm{ng} / \mathrm{cm}^{3}\right)$ and $\mu_{\mathrm{q}}\left(2.947 \times 10^{20} \mathrm{ng} /(\mathrm{cm} . \mathrm{s})\right)$ are the density and shear modulus of the AT-cut quartz crystal, respectively. Generally, a film is considered rigid if the measured $\Delta \mathrm{f}_{\mathrm{n}} / \mathrm{n}$ is independent of the overtone order [43] and if $\Delta D_{n}$ is very small relative to $\Delta f_{n} / n$. The criterion $\Delta D_{n} /\left(-\Delta f_{n} / n\right)<$ $5 \times 10^{-8} \mathrm{HZ}^{-1}$ is used here.

When the overtone-order-n normalized frequency shifts spread between different orders, and when significant $\Delta D_{n}$ are recorded, the viscoelastic properties of the film need to be considered [45,46]. A Voigt-Kelvin-based model [44], which relates $\Delta \mathrm{f}_{\mathrm{n}}$ and $\Delta \mathrm{D}_{\mathrm{n}}$ to areal mass density $\mathrm{m}_{\mathrm{fQCM}-\mathrm{D}}$ and viscoelasticity properties of the film, was typically used to analyze data for soft but laterally homogeneous films. Under a simplified condition, when $\mathrm{k}_{\mathrm{f}} \mathrm{d}_{\mathrm{f}}<<1$, $\mathrm{k}_{\mathrm{f}}$ is the acoustic wave number, $d_{f}$ is the film thickness), the viscoelastic model can be expressed as $[43,47]:$

$$
\begin{aligned}
& \frac{\Delta f_{n}}{n} \approx-\frac{1}{C} m_{f_{Q C M_{D}}}\left(1-n w_{f} \rho_{l} \eta_{l} \frac{G^{\prime \prime}}{\rho_{f}\left({\mathrm{G}^{\prime}}^{2}+\mathrm{G}^{\prime \prime^{2}}\right)}\right), \\
& \Delta D_{n} \approx 2 \frac{n}{f C} m_{f_{Q C M_{D}} n w_{f} \rho_{l} \eta_{l} \frac{\mathrm{G}^{\prime}}{\rho_{f}\left({G^{\prime}}^{2}+\mathrm{G}^{\prime \prime^{2}}\right)},}
\end{aligned}
$$


where $\mathrm{C}$ is the mass sensitivity constant $\left(C=\frac{\sqrt{\rho_{q} \mu_{q}}}{2 f_{F}^{2}}\right), \mathrm{w}_{\mathrm{f}}=2 \pi \mathrm{f}_{\mathrm{F}}$ is the angular fundamental response frequency, $\eta_{1}$ and $\rho_{1}$ are the viscosity and density of the liquid, respectively. $G=\mathrm{G}^{\prime}+\mathrm{iG}^{\prime \prime}$ is the complex shear modulus parameter of the adsorbate. $\mathrm{G}^{\prime}$ is the storage modulus parameter, which is related to the material elasticity, and $\mathrm{G}^{\prime \prime}=2 \pi n f_{\mathrm{F}} \eta$, is the loss modulus parameter, which describes viscous energy dissipation in the material.

When the surface is rough, the viscoelastic model for homogeneous films may not be adequate to account for $\Delta \mathrm{f}_{\mathrm{n}}$ and $\Delta \mathrm{D}_{\mathrm{n}}$. In particular, water can be bound to the rough surface and act as a rigid adsorbate. Therefore, $\Delta \mathrm{f}_{\mathrm{n}}$ will not only depend on the amount of particle attachment, but also on the amount of entrapped water between particles and within the open space of the rough surface [48]. The dependence of the QCM-D response on the interface topography has been previously derived for the case of strong roughness where surface corrugations are not significantly smaller than the decay length of shear wave $(\delta)[25,48,49]$ :

$$
\begin{gathered}
\delta=\sqrt{\frac{\eta_{l}}{\pi n f_{F} \rho_{l}}}, \\
\frac{\Delta f_{n}}{n}=-\frac{2 f_{F}^{2} \rho_{l}}{\sqrt{\mu_{q} \rho_{q}}} \operatorname{Re}\left(\frac{1}{q_{0}}+d_{e f f}^{*}\right), \\
\Delta D_{n}=-\frac{4 f_{F} \rho_{l}}{\sqrt{\mu_{q} \rho_{q}}} \operatorname{Im}\left(\frac{1}{q_{0}}+d_{e f f}^{*}\right), \\
d_{e f f}^{*}=\frac{L_{r}}{\xi^{2} q_{1}^{2}}-\frac{1}{W} \frac{1}{\xi^{2} q_{1}^{2}}\left\{\frac{2 q_{0}}{q_{1}}\left[\cosh \left(q_{1} L_{r}\right)-1\right]+\sinh \left(q_{1} L_{r}\right)\right\} \\
q_{0}=\sqrt{\frac{i n 2 \pi f_{F} \rho_{l}}{\eta}}, \\
W=q_{1} \cosh \left(q_{1} L_{r}\right)+q_{0} \sinh \left(q_{1} L_{r}\right)
\end{gathered}
$$


Here, $L_{r}$ is the vertical roughness length parameter. $\xi$ is the permeability length parameter, which is related to the porosity of a rough surface layer [50]. Re and Im denote the real and imaginary parts of the complex number, respectively. In this model, the first terms in the parentheses on the right-hand-sides of equation 5-1 and 5-2 describe the QCM-D response on smooth surfaces. The second terms of these two equations describe the change in frequency and dissipation caused by the interaction of liquid with rough surfaces [25]. This model, however, does not take into account the viscoelastic effects of soft films.

For the case of nanoparticle attachment onto SCTF-coated QCM-D sensors, both viscoelastic effect and surface roughness contribute to the frequency and dissipation shifts [48].

$$
\begin{aligned}
& \frac{\Delta f_{n}}{n}=-\frac{2 f_{F}^{2} \rho_{l}}{\sqrt{\mu_{q} \rho_{q}}} \operatorname{Re}\left(d_{e f f}^{*}\right)-\frac{1}{C} m_{f Q C M-D}\left(1-n w_{f} \rho_{l} \eta_{l} \frac{G^{\prime \prime}}{\rho_{f}\left(G^{\prime 2}+G^{\prime \prime 2}\right)}\right) \\
& \frac{\Delta D_{n}}{n}=-\frac{4 f_{F} \rho_{l}}{n \sqrt{\mu_{q} \rho_{q}}} \operatorname{Im}\left(d_{e f f}^{*}\right)+2 \frac{1}{f C} m_{f Q C M-D} n w_{f} \rho_{l} \eta_{l} \frac{\mathrm{G}^{\prime}}{\rho_{f}\left(G^{\prime 2}+\mathrm{G}^{\prime \prime 2}\right)}
\end{aligned}
$$

In this model $\mathrm{G}^{\prime}, \mathrm{G}^{\prime \prime}, \mathrm{m}_{\mathrm{fQCM}-\mathrm{D}}, \mathrm{L}_{\mathrm{r}}, \xi$ are parameters of interests, where $\mathrm{m}_{\mathrm{fQCM}-\mathrm{D}}$ defines areal mass density, $\mathrm{G}^{\prime}$ and $\mathrm{G}^{\prime \prime}$ define viscoelasticity properties of the film, and $\mathrm{L}_{\mathrm{r}}$ and $\xi$ describe the surface roughness properties. $L_{r}$ and $\xi^{2}$ describe the average vertical roughness length parameter, and the permeability parameter of a porous media respectively. Considering the relatively low concentration of $\mathrm{TiO}_{2} \mathrm{NP}$ used in the study (i.e., $5 \mathrm{ppm}$ ), we assumed that $\mathrm{G}^{\prime \prime}$ was constant for each overtone, and can be calculated based on the viscosity of pure water. This assumption is consistent with a recent viscoelastic analysis of nanoparticle deposition using QCM-D [3], where the viscosity of multiwalled carbon nanotubes (MWNTs) layer attached to 
QCM-D sensor were found to remain constant and close to the viscosity of water. Note that the dissipation shift $\left(\Delta D_{n}\right)$ was normalized with respect to overtone numbers in equation (6-2) to be mathematically consistent with the normalized frequency shift $\left(\Delta \mathrm{f}_{\mathrm{n}} / \mathrm{n}\right)$. The dissipation shift was typically not normalized when provided by the QCM-D software. Comparison between values of $\Delta \mathrm{f}_{\mathrm{n}} / \mathrm{n}$ and $\Delta \mathrm{D}_{\mathrm{n}}$ recorded by the QCM-D experiment and the results of best-model calculations for all recorded overtone numbers $(n=3,5,7,9,11,13)$, using the model equations given above, provided best-match model parameters for $\mathrm{G}^{\prime}, \mathrm{m}_{\mathrm{fQCM}-\mathrm{D}}, \mathrm{L}_{\mathrm{r}}, \xi$, as a function of time over the duration of the experiment. The model equations (Eq. 6) were implemented as user-definable expressions with model parameters for $\mathrm{G}^{\prime}, \mathrm{m}_{\mathrm{fQCM}-\mathrm{D}}, \mathrm{L}_{\mathrm{r}}, \xi$, and a non-linear mean squared error (MSE) tool in the WVASE software (J.A. Woollam Co., Inc.) was used to generate and compare model-calculated and experimental $\Delta \mathrm{f}_{\mathrm{n}} / \mathrm{n}$ and $\Delta \mathrm{D}_{\mathrm{n}} / \mathrm{n}$ data, varying model parameters until bestmatch was reached.

\section{4- Results and Discussion}

\section{4-1- Nanoparticles and surface characterization}

The hydrodynamic diameter of $\mathrm{TiO}_{2} \mathrm{NPs}$ were between 5 to $35 \mathrm{~nm}$ (Figure 2). The Zeta potential of the $\mathrm{TiO}_{2} \mathrm{NP}$ in the solution $(\mathrm{pH} 7)$ was $-17.27 \mathrm{mV}( \pm 2.08)$. The properties of the SCTF (thickness, slanting angle, and slanting plane, depolarization factors $\left(\mathrm{q}_{\mathrm{z}}, \mathrm{q}_{\mathrm{xy}}\right)$, and the constituent

material volume fractions $\left(f_{\text {void }}, f_{\text {liquid }}, f_{\mathrm{Si}}, f_{\mathrm{TiO}_{2}}\right)$ in air, and in water in the presence of $\mathrm{TiO}_{2} \mathrm{NP}$ are presented in Table 1. Figure 3 depicts top and cross-sectional high resolution SEM images of the alumina-coated Si-SCTF coated QCM sensor. 


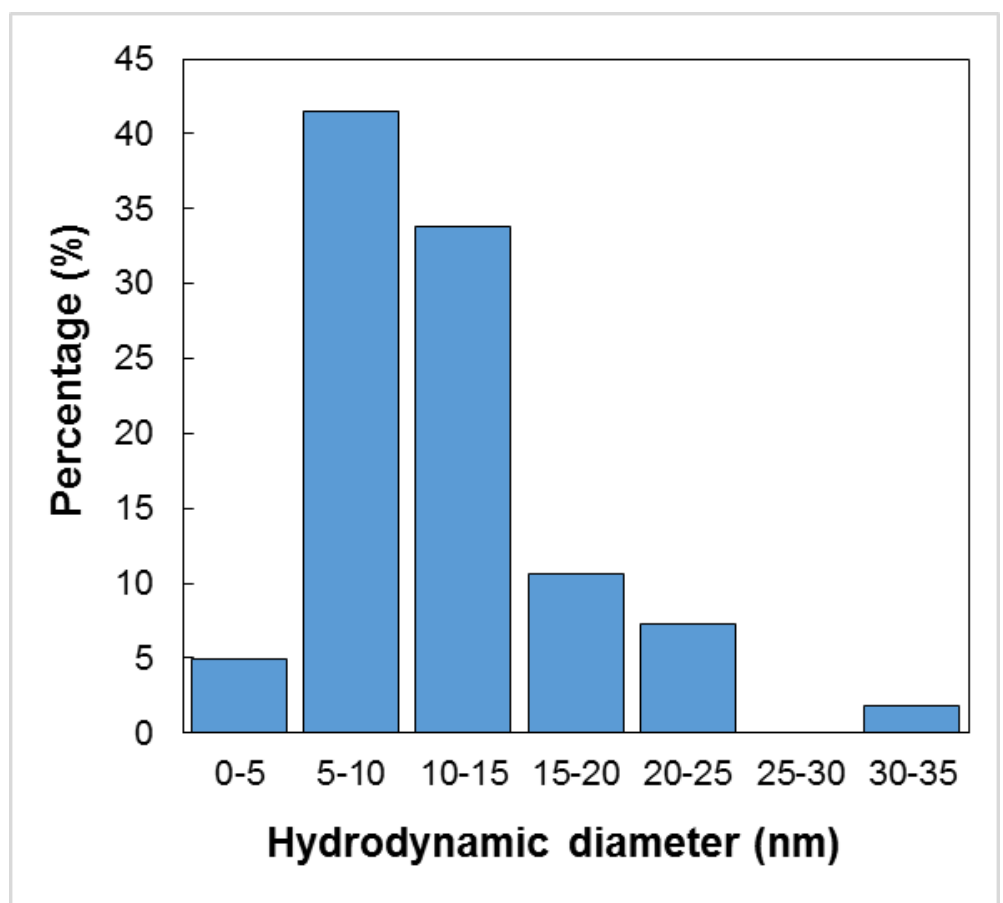

Figure 2: Hydrodynamic diameter distribution of $\mathrm{TiO}_{2} \mathrm{NP}$ in the solution.

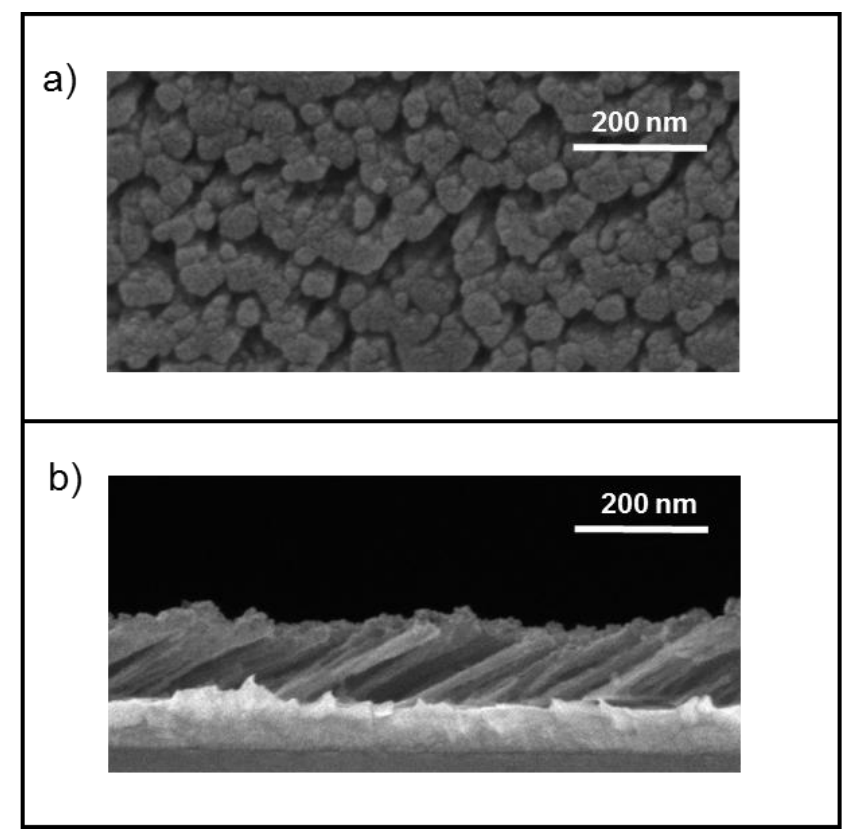

Figure 3: SEM images of $\mathrm{Al}_{2} \mathrm{O}_{3}$-SCTF on QCM-D sensor. a) Top view. b) Cross-sectional view. 
Table 1: GE measurements for alumina coated Si-SCTF coated QCM sensor in air, water, and with deposited $\mathrm{TiO}_{2} \mathrm{NP}$. The error bars correspond to the usual $90 \%$ parameter confidence interval.

\begin{tabular}{clccc}
\hline & & SCTF in air & SCTF in water & $\begin{array}{c}\text { SCTF and } \\
\text { TiO }_{2} \text { NP in water }\end{array}$ \\
\hline \multirow{2}{*}{$\begin{array}{c}\text { Structural } \\
\text { Parameters }\end{array}$} & Thickness $(\mathbf{n m})$ & $113 \pm 2$ & $111 \pm 1$ & $111^{\mathrm{a}} \pm 1$ \\
& Slanting angle $\left(^{\circ}\right)$ & $63 \pm 2$ & $62 \pm 1$ & $62^{\mathrm{a}} \pm 1$ \\
& Slanting plane $\left(^{\circ}\right)$ & $227 \pm 2$ & $220 \pm 1$ & $220^{\mathrm{a}} \pm 1$ \\
\hline Depolarization & $\mathbf{q}_{\mathbf{z}}$ & $0.170 \pm 0.009$ & $0.072 \pm 0.022$ & $0.072^{\mathrm{a}} \pm 0.022$ \\
Factors & $\mathbf{q}_{\mathbf{x y}}$ & $0.378 \pm 0.017$ & $0.374 \pm 0.007$ & $0.374^{\mathrm{a}} \pm 0.007$ \\
\hline & $\mathbf{f}_{\text {void }}$ & $77 \pm 1$ & - & - \\
Constituent's & $\mathbf{f}_{\text {liquid }}$ & - & $79 \pm 1$ & $77 \pm 1$ \\
Fraction (\%) & $\mathbf{f}_{\mathrm{Si}}$ & $23 \pm 1$ & $21 \pm 1$ & $21 \pm 1$ \\
& $\mathbf{f}_{\mathrm{TiO}_{\mathbf{2}}}$ & - & - & $2.0 \pm 0.2$ \\
\hline
\end{tabular}

a: Parameters kept constant as SCTF in water, keeping the $\mathrm{f}_{\mathrm{TiO}_{2}}$ the only best-match model parameter.

\section{4-2- $\mathrm{TiO}_{2} \mathrm{NP}$ deposition onto flat surfaces}

Figure 4 shows the frequency and dissipation change of the fifth harmonic overtone in the QCM-D experiment with a flat surface. A decrease in frequency and an increase in dissipation was observed following the introduction of 5 ppm $\mathrm{TiO}_{2} \mathrm{NP}$ at $\mathrm{pH} 7$ into the QCM-D flow cell. Immediately after the $\mathrm{TiO}_{2} \mathrm{NP}$ suspension was introduced (Stage II), a sharp drop in frequency and a sharp increase in dissipation were observed, until stabilization. At the end of 20 min of exposure, a $12 \mathrm{~Hz}$ drop of frequency and a $1.6 \times 10^{-6}$ increase of dissipation for the fifth harmonic overtone were observed. The change in dissipation was more than $5 \%$ of the change in frequency, and $\Delta \mathrm{f}_{\mathrm{n}} / \mathrm{n}$ were different for different overtones, which are the indications of viscoelastic effects. Thus, the areal mass density of the attached particles was calculated using the Voigt-Kelvin model (QTools software, Biolin Scientific AB, Stockholm, Sweden) for all the harmonic overtones except the dissipation data for the $7^{\text {th }}$ overtone [44].

Figure 5 illustrates the areal mass density of deposited $\mathrm{TiO}_{2} \mathrm{NP}$ on smooth flat aluminacoated QCM-D sensor calculated based on the Voigt-Kelvin model. The mass of deposited $\mathrm{TiO}_{2} \mathrm{NP}$ gradually increased after the introduction of $\mathrm{TiO}_{2} \mathrm{NP}$, and reached $304 \mathrm{ng} / \mathrm{cm}^{2}$ after 20 
min of solution injection. Although $\mathrm{TiO}_{2} \mathrm{NP}$ in the solution is negatively charged, the surface charge of our alumina-coated QCM-D sensors was not measured. A positive charge of $25 \mathrm{mV}$ was reported for a thin ALD layer of alumina on the surface of a silicon wafer at $\mathrm{pH} 7 \mathrm{in} 1 \mathrm{mM}$ $\mathrm{KCl}$ [51], which is close to the conditions here. Assuming that the alumina-coated QCM-D sensor was also positively charged here, electrostatic attraction between $\mathrm{TiO}_{2} \mathrm{NP}$ and the alumina-coated QCM-D sensor is expected based on DLVO theory[52], which explains the observed deposition.

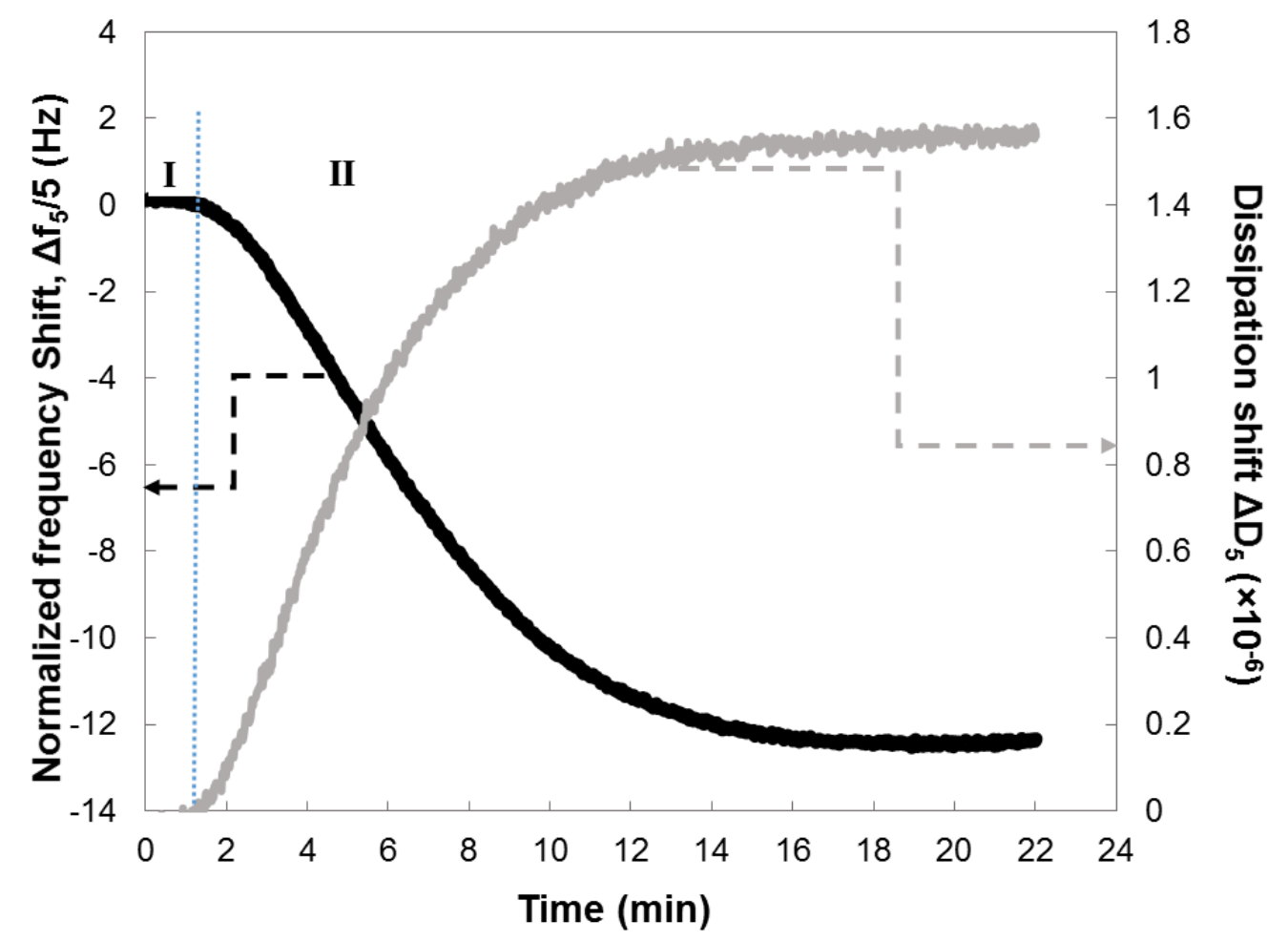

Figure 4: Normalized frequency shift $\left(\Delta \mathrm{f}_{\mathrm{n}} / \mathrm{n}\right)$ and dissipation shift $\left(\Delta \mathrm{D}_{\mathrm{n}}\right)$ of fifth overtone during injection of nanopure water in Stage I and $5 \mathrm{ppm} \mathrm{TiO}_{2} \mathrm{NP}$ in Stage II over the alumina-coated flat QCM sensor. 


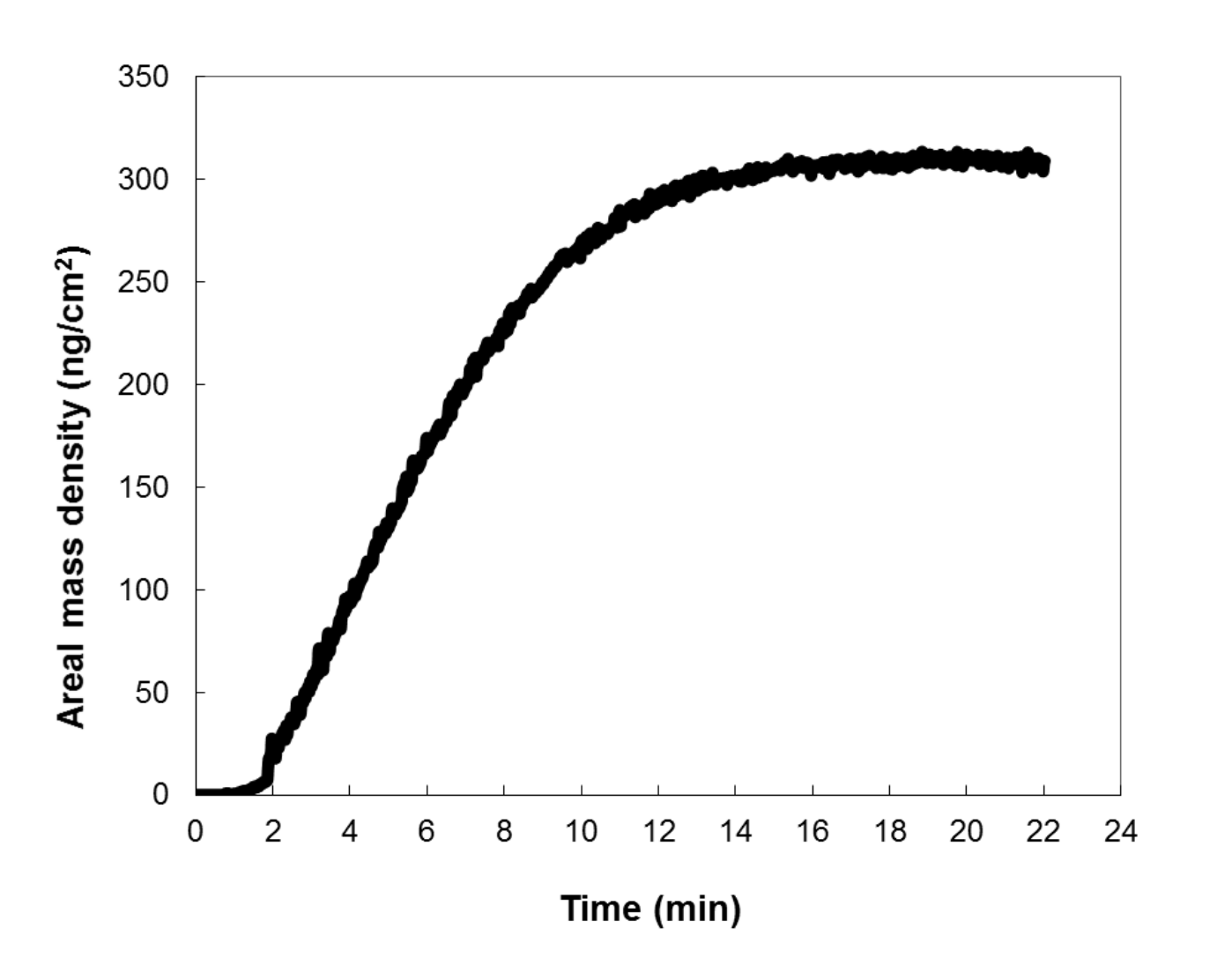

Figure 5: Areal mass density of deposited $\mathrm{TiO}_{2} \mathrm{NP}$ onto the alumina-coated flat QCM-D sensor calculated using the Voigt-Kelvin Model.

\section{4-3- Deposition of $\mathrm{TiO}_{2} \mathrm{NP}$ onto rough surfaces}

\section{4-3-1-Combined roughness-viscoelasticity analysis}

Figure 6 depicts the frequency and dissipation change of all overtone numbers for the QCM-D experiment with a rough surface. Following the introduction of $\mathrm{TiO}_{2} \mathrm{NP}$ solution (Stage II), a significant decrease in frequency and a simultaneous increase in dissipation were observed. For example, a $125.85 \mathrm{~Hz}$ drop in frequency and a $17.76 \times 10^{-6}$ increase in dissipation were observed for the fifth overtone after exposure to $\mathrm{TiO}_{2} \mathrm{NP}$ solution for 125 minutes. Although the measured frequency drop and dissipation increase after $125 \mathrm{~min}$ of exposure on rough surfaces 
was about 10 times larger than the maximum frequency drop on flat surfaces, neither frequency nor dissipation shifts reached stabilization. The surprisingly higher frequency drop led to our hypothesis that the trapped liquid in the corrugation of rough surfaces with attached nanoparticles may also partially contribute to the frequency drop. Therefore, a roughness based model (Eq. 5) was implemented to interpret the QCM-D data. In addition to a significant drop, $\Delta \mathrm{f}_{\mathrm{n}} / \mathrm{n}$ were different for different overtone numbers (Figure 6), indicating the presence of viscoelastic effects. Because $\Delta D_{n}$ was more than $5 \%$ of $\Delta f_{n} / n$, viscoelastic effects should be considered when analyzing QCM-D data (Eq. 3).

The combined roughness and viscoelastic model (Eq. 6) was applied to simulate the QCM-D data for $\mathrm{TiO}_{2} \mathrm{NP}$ deposition onto alumina-coated Si-SCTF surfaces. The values of the best-match model parameters $\left(\mathrm{G}^{\prime}, \mathrm{m}_{\mathrm{fQCM}-\mathrm{D}}, \mathrm{L}_{\mathrm{r}}, \xi\right)$, as well as R-squared data, at selected time points are provided in Table 2 and Figure 7 . Figure 8 presents a comparison between best-match model calculated $\left(\Delta \mathrm{fm}_{\mathrm{n}} / \mathrm{n}, \Delta \mathrm{Dm}_{\mathrm{n}} / \mathrm{n}\right)$ and experimental data $\left(\Delta \mathrm{fe}_{\mathrm{n}} / \mathrm{n}, \Delta \mathrm{De}_{\mathrm{n}} / \mathrm{n}\right)$. As shown in Table 2, R-squared values are 0.99 for $\Delta f_{n} / n$, and $>0.93$ for $\Delta D_{n} / n$ except for the first time slice at 25 min, where the R-squared value for $\Delta \mathrm{D}_{\mathrm{n}} / \mathrm{n}$ is 0.66 . The experimental data $\left(\Delta \mathrm{fe}_{\mathrm{n}} / \mathrm{n}, \Delta \mathrm{De}_{\mathrm{n}} / \mathrm{n}\right)$ show linear and non-linear behavior as a function of $n$, which provide sensitivity to the 4 parameters by using the combined model that we suggest here. The combined model $\left(\Delta \mathrm{fm}_{\mathrm{n}} / \mathrm{n}, \Delta \mathrm{Dm}_{\mathrm{n}} / \mathrm{n}\right)$ provides flexibility to reproduce all the observed linear and non-linear contributions.

Based on the simulation results (Figure 7a), after only 20 min exposure to $\mathrm{TiO}_{2} \mathrm{NP}$ suspension, $\mathrm{m}_{\mathrm{fQCM}-\mathrm{D}}$ of attached $\mathrm{TiO}_{2} \mathrm{NP}$ on the surface reached $316 \mathrm{ng} / \mathrm{cm}^{2}$, which is above the stabilized areal mass density of attached $\mathrm{TiO}_{2} \mathrm{NP}$ on flat surfaces. After 125 min of exposure, the $\mathrm{m}_{\mathrm{fQCM}-\mathrm{D}}$ increased to $1831 \mathrm{ng} / \mathrm{cm}^{2}$, which was about 6 times larger than the stabilized areal mass density observed on the flat-alumina coated QCM-D sensor. We note that stabilization of the 
deposition process had not been reached in our experiment. According to the SEM images (Figure 3) and the GE modeling results, the surface area of a SCTF coated QCM-D sensor is approximately 4 times higher than that of the same but flat QCM-D sensor, which partially explains the increased attachment. In addition, the presence of surface roughness also could substantially increase the attractive energy between $\mathrm{TiO}_{2} \mathrm{NP}$ and the model rough sensor surface, thereby enhancing particle deposition, consistent with multiple previous studies on the role of surface roughness on particle deposition [21,53-58].

During $\mathrm{TiO}_{2} \mathrm{NP}$ suspension exposure, the storage modulus $\mathrm{G}^{\prime}$ of attached nanoparticles increased from $1.35 \times 10^{6}$ to $1.48 \times 10^{6}$ (Figure $7 \mathrm{~b}$ ), indicating a slight increase in the elasticity of the attached film, which is consistent with findings reported by Yi et al. [3]. During the experiment, $\xi$ decreased from $487 \mathrm{~nm}$ to $348 \mathrm{~nm}$ (Figure 7c), indicating a reduction of the permeability of the SCTF while $\mathrm{TiO}_{2} \mathrm{NP}$ deposited into the void space of the alumina coated SiSCTF QCM-D surface. $\mathrm{L}_{\mathrm{r}}$, the model parameter for vertical roughness length, also varied during nanoparticle deposition. For example, $\mathrm{L}_{\mathrm{r}}$ was found around $100 \mathrm{~nm}$ after $25 \mathrm{~min}$, which was increased to more than $200 \mathrm{~nm}$ after $120 \mathrm{~min}$ (Figure 7d). The increase in $\mathrm{L}_{\mathrm{r}}$ can be understood as the increase in the surface roughness due to the continued attachment of $\mathrm{TiO}_{2} \mathrm{NP}$ onto the surface of the nanostructures. 


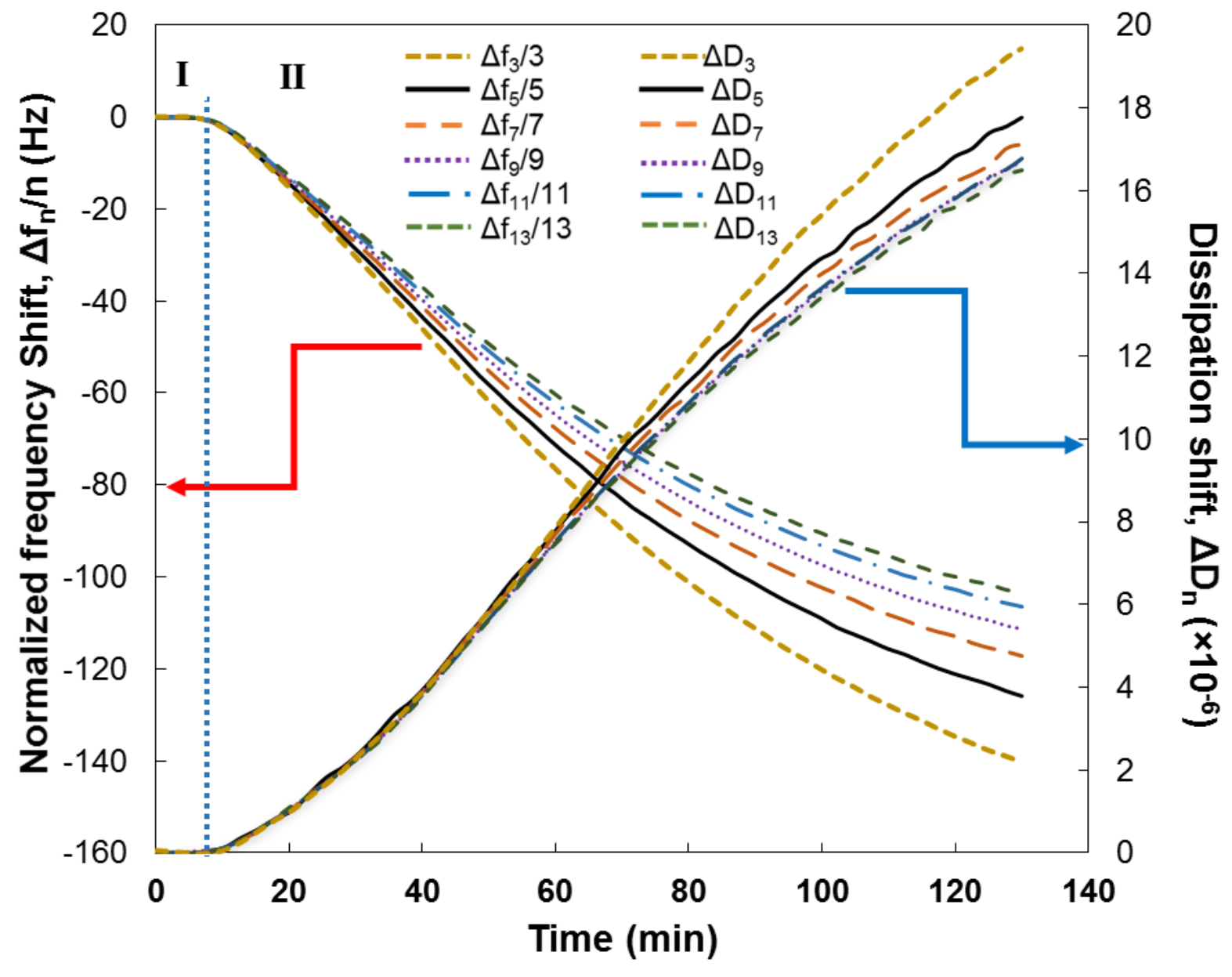

Figure 6: Normalized frequency shift $\left(\Delta \mathrm{f}_{\mathrm{n}} / \mathrm{n}\right)$ and dissipation shift $\left(\Delta \mathrm{D}_{\mathrm{n}}\right)$ of different overtones during introduction of nanopure water in Stage I, and 5 ppm $\mathrm{TiO}_{2} \mathrm{NP}$ in stage II onto alumina-coated Si-SCTF deposited onto a QCM-D sensor. 
Table 2: Best-match model parameter values at different time points for the combined effects of surface roughness and viscoelasticity. The error bars correspond to the $90 \%$ parameter confidence interval.

\begin{tabular}{|c|c|c|c|c|c|c|}
\hline \multirow{3}{*}{$\begin{array}{l}\text { Time } \\
\text { (min) }\end{array}$} & \multicolumn{4}{|c|}{ Parameters } & & \\
\hline & \multirow{2}{*}{$\begin{array}{l}m_{\text {fQCM_D }} \\
\left(\mathrm{ng} / \mathrm{cm}^{2}\right)\end{array}$} & \multirow{2}{*}{$\mathbf{G}^{\prime}(\mathrm{Pa})$} & \multirow{2}{*}{$\mathrm{L}_{\mathrm{r}}(\mathrm{nm})$} & \multirow{2}{*}{$\xi(\mathrm{nm})$} & \multicolumn{2}{|c|}{$\mathbf{R}^{2}$} \\
\hline & & & & & $\Delta f_{n} / n$ & $\Delta D_{n} / n$ \\
\hline 25 & $316 \pm 35$ & $1.35 \times 10^{6} \pm 0.14 \times 10^{6}$ & $107 \pm 40$ & $487 \pm 303$ & 0.99 & 0.66 \\
\hline 55 & $995 \pm 27$ & $1.35 \times 10^{6} \pm 0.09 \times 10^{6}$ & $175 \pm 21$ & $484 \pm 76$ & 0.99 & 0.93 \\
\hline 85 & $1460 \pm 16$ & $1.37 \times 10^{6} \pm 0.05 \times 10^{6}$ & $208 \pm 8$ & $416 \pm 20$ & 0.99 & 0.97 \\
\hline 115 & $1735 \pm 23$ & $1.46 \times 10^{6} \pm 0.08 \times 10^{6}$ & $216 \pm 8$ & $360 \pm 16$ & 0.99 & 0.98 \\
\hline 130 & $1831 \pm 21$ & $1.48 \times 10^{6} \pm 0.07 \times 10^{6}$ & $222 \pm 8$ & $348 \pm 14$ & 0.99 & 0.99 \\
\hline
\end{tabular}




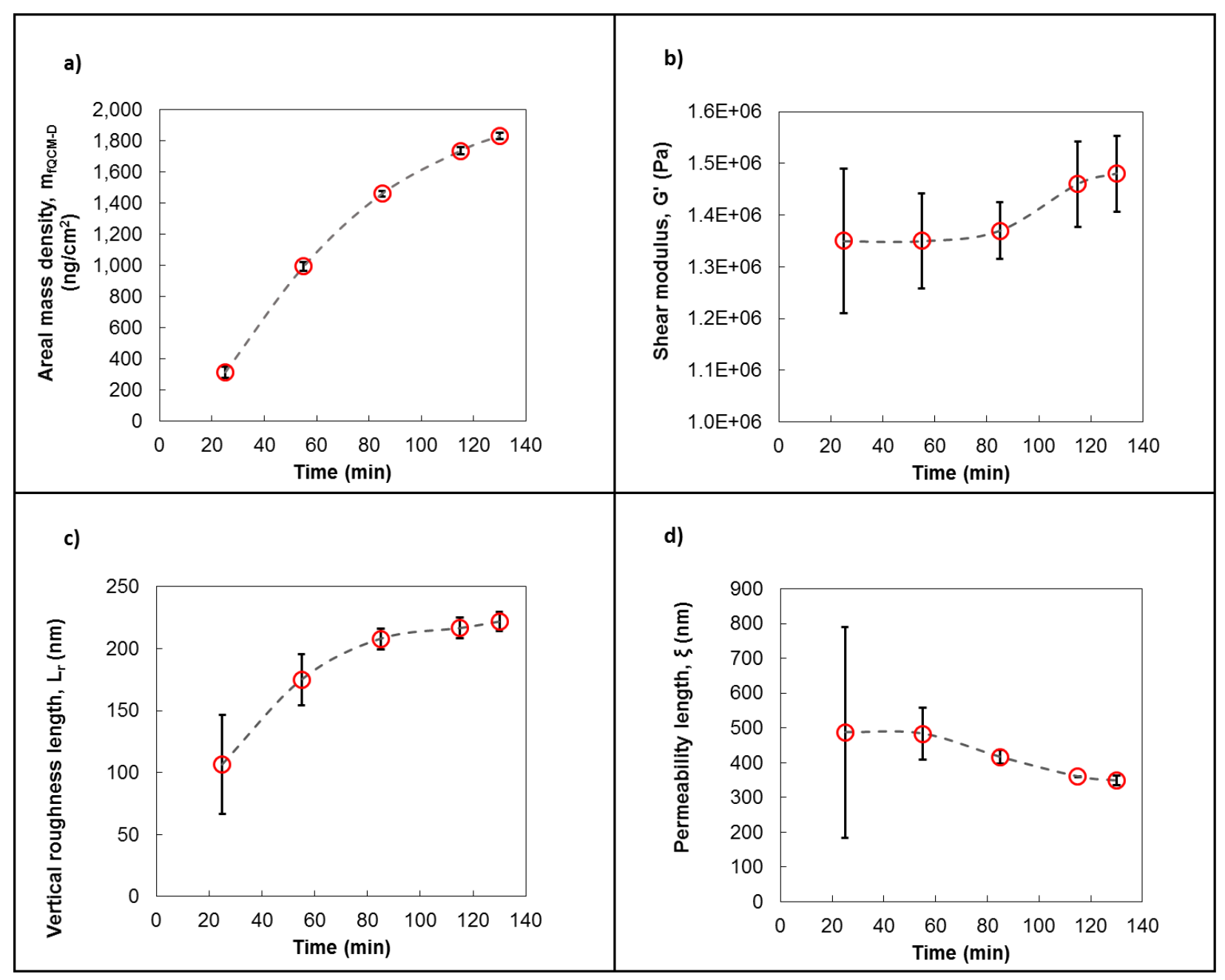

Figure 7: Best-match model parameter values at different time point for the combined effect of surface roughness and viscoelastic film. 


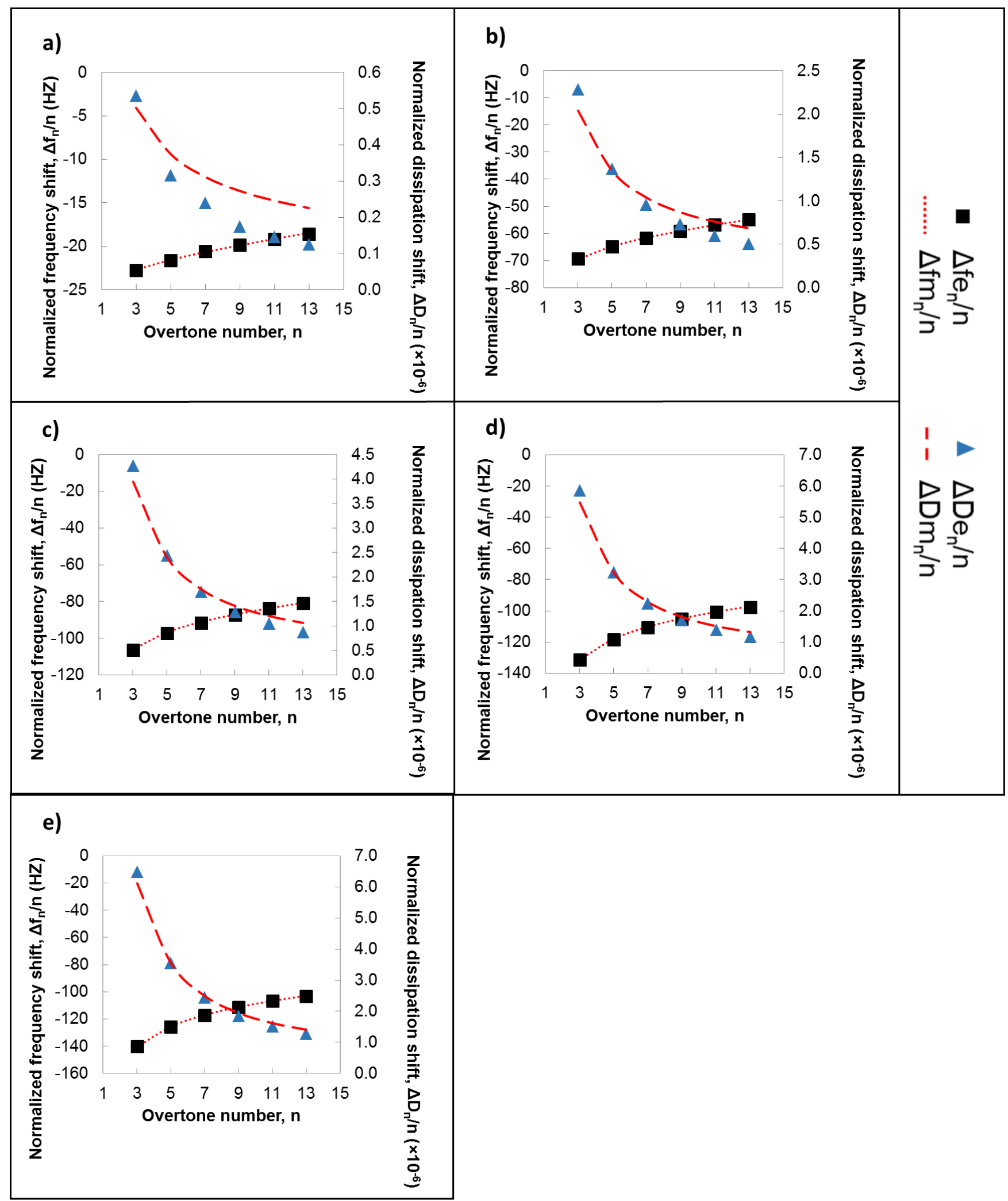


Figure 8: Experimental (symbols; $\left.\Delta \mathrm{fe}_{\mathrm{n}} / \mathrm{n}, \Delta \mathrm{De}_{\mathrm{n}} / \mathrm{n}\right)$ and best-match model calculated $\left(\Delta \mathrm{fm}_{\mathrm{n}} / \mathrm{n}, \Delta \mathrm{Dm}_{\mathrm{n}} / \mathrm{n}\right)$ normalized frequency and dissipation shift data for overtones 3 to 13 after a) $25 \mathrm{~min}$, b) $55 \mathrm{~min}$, c) $85 \mathrm{~min}$, d) $115 \mathrm{~min}$, and e) $130 \mathrm{~min}$ of $\mathrm{TiO}_{2} \mathrm{NP}$ adsorption experiment onto alumina-coated Si-SCTF fabricated onto a QCM-D sensor. The best-match model calculations include the combined effects of surface roughness, and a viscoelastic film.

\section{4-3-2-GE Analysis}

The AB-EMA model (Figure 1b) was used to quantify the attachment of $\mathrm{TiO}_{2} \mathrm{NP}$ onto the model rough SCTF surface based on the Mueller matrix element spectra measured by GE. Here, $\mathrm{f}_{\mathrm{TiO}_{2}}$ was the only best-match model parameter required to minimize the differences between best-match model calculated and measured Mueller matrix data. Figure 9 depicts selected $\mathrm{M}_{\mathrm{ij}}$ spectra used for the AB-EMA model calculations, before and after $\mathrm{TiO}_{2} \mathrm{NP}$ attachment to alumina-coated Si-SCTF fabricated onto a QCM-D sensor.

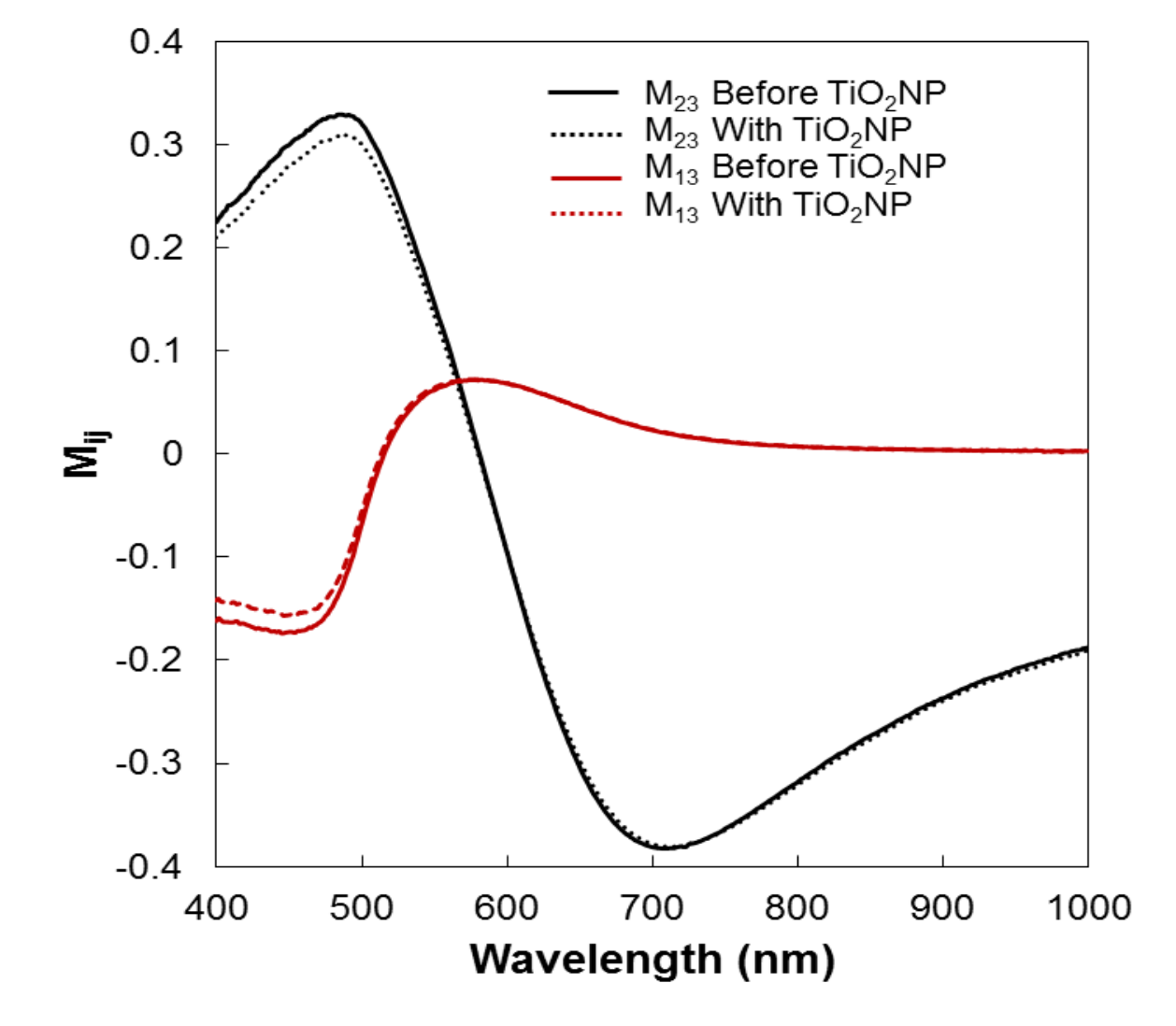

Figure 9: Select $\mathrm{M}_{\mathrm{ij}}$ spectra for before $\mathrm{TiO}_{2} \mathrm{NP}$ adsorption and at the end of $\mathrm{TiO}_{2} \mathrm{NP}$ adsorption. 
The areal mass density measured by GE can be estimated based on this equation:

$$
m_{f_{G E}}=H f_{\mathrm{TiO}_{2}} \rho_{\mathrm{TiO}_{2}}
$$

where $\mathrm{H}$ is the thickness of SCTF, $\rho_{\mathrm{TiO}_{2}}$ is the density of $\mathrm{TiO}_{2} \mathrm{NP}(3.9 \mathrm{~g} / \mathrm{mL})$ [59]. Figure 10 depicts the change of areal mass density determined by the GE technique, $\mathrm{m}_{\mathrm{fGE}}$, over time. Also included in the Figure 10 are the best-match model parameters for the areal mass density of $\mathrm{TiO}_{2} \mathrm{NP}$ calculated using the combined viscoelastic and roughness model (Eq. 6). It was found that $\mathrm{m}_{\mathrm{fGE}}$ is nearly consistently about half of $\mathrm{m}_{\mathrm{fQCM}-\mathrm{D}}$, over the course of experiments.

\section{4-3-3-Voigt-Kelvin mode Analysis}

Figure 10 further includes the best-match model parameters for the areal mass density of $\mathrm{TiO}_{2} \mathrm{NP}$ calculated using the Voigt-Kelvin model $\mathrm{m}_{\mathrm{fVK}}$, (QTools software, Biolin Scientific AB, Stockholm, Sweden). All of the harmonic overtones were used for the calculation [44]. It was found that $\mathrm{m}_{\mathrm{fVK}}$ is about 6 times larger than $\mathrm{m}_{\mathrm{fGE}}$ and approximately 2.6 times larger than $\mathrm{m}_{\mathrm{fQCM}}$ -

D.

\section{4-3-4-Discussion}

Because GE is insensitive to effects of mechanical water entrapment variations in roughness spaces, $\mathrm{m}_{\mathrm{fGE}}$ was considered here to reflect most closely the true areal mass density of the attached $\mathrm{TiO}_{2} \mathrm{NP}$ onto the surface. Although the Voigt-Kelvin model considers the viscoelastic properties of the attached film, it is not suitable to differentiate between the frequency and dissipation shifts due to $\mathrm{TiO}_{2} \mathrm{NP}$ attachment or water entrapment. For nanoparticle deposition onto rough surfaces, two different types of water entrapment are involved. First, the structure geometry of the roughness can result in water entrapment, or roughness-retained water. 
Second, water could closely associate with nanoparticles due to hydration bonding. The VoigtKelvin model does not allow for differentiation of either type of water entrapment, which therefore provided a highly over estimated areal mass density of attached $\mathrm{TiO}_{2} \mathrm{NP}$ when compared with $\mathrm{m}_{\mathrm{fGE}}$. On the other hand, $\mathrm{m}_{\mathrm{fQCM}-\mathrm{D}}$ obtained using the combined viscoelastic and roughness model (Eq. 6) is much lower than $\mathrm{m}_{\mathrm{fVK}}$, indicating that the model was successfully excluded the contribution of roughness-retained water on measured frequency and dissipation shifts. Although we believe this work is the first to discuss the role of roughness-retained water on particle deposition in model rough surfaces, the effect of roughness-retained water on QCMD frequency and dissipation responses was previously discussed [49,60,61]. These studies demonstrated that the effective areal mass measured by QCM-D includes substantial amounts of trapped water by rough surfaces, consistent with our findings for rough surface.

\section{4-4-Porosity estimation}

Water closely associated with $\mathrm{TiO}_{2} \mathrm{NP}$ cannot be excluded by the combined viscoelastic and roughness model (Eq. 6), but may explain the difference between areal mass parameters obtained from QCM-D and GE. $\mathrm{TiO}_{2} \mathrm{NP}$ used in this study was stabilized with polyacrylate Sodium, which has the ability to absorb water and swell. In addition, it is very common for nanoparticles to form aggregates in water, as demonstrated by larger sized particles in the size distribution of this study (Figure 2). Water associated within the pore spaces inside aggregates can also contribute to frequency shifts, but was not accounted by the combined roughnessviscoelasticity model in Eqs. (6). In analogy to previous work combining areal mass density values obtained by QCM-D and GE $[37,38,65,66]$, parameters $\mathrm{m}_{\mathrm{fGE}}$ and $\mathrm{m}_{\mathrm{fQCM}-\mathrm{D}}$ permit the derivation of a porosity value of the attached $\mathrm{TiO}_{2} \mathrm{NP}$ layer onto the SCTF surface. Such estimation simply follows from geometric fraction or density rationing. The adsorbate content 
mass and volume fraction $\left(f_{o, m}, f_{o, v}\right)$ quantitatively describe the porosity of a thin layer $[37,38,62,63]$.

$$
\begin{gathered}
f_{o, m}=\frac{m_{f G E}}{m_{f Q C M-D}} \\
f_{o, V}=\frac{\rho_{l}}{\rho_{T i O_{2}}} \frac{f_{o, m}}{1-f_{o, m}+f_{o, m} \frac{\rho_{l}}{\rho_{T i O_{2}}}},
\end{gathered}
$$

As it is shown in Figure 10, the thereby estimated mass and volume based fraction porosity parameters of attached $\mathrm{TiO}_{2} \mathrm{NP}$ on alumina-coated $\mathrm{Si}$-SCTF fabricated onto the QCM-D sensor remained approximately constant as 0.42 and 0.16 , respectively, over the course of the experiment. This finding suggested that a continuous entanglement of water within the pore space of attaching $\mathrm{TiO}_{2} \mathrm{NP}$ due to hydration bonding occurred over the course of the experiment. 


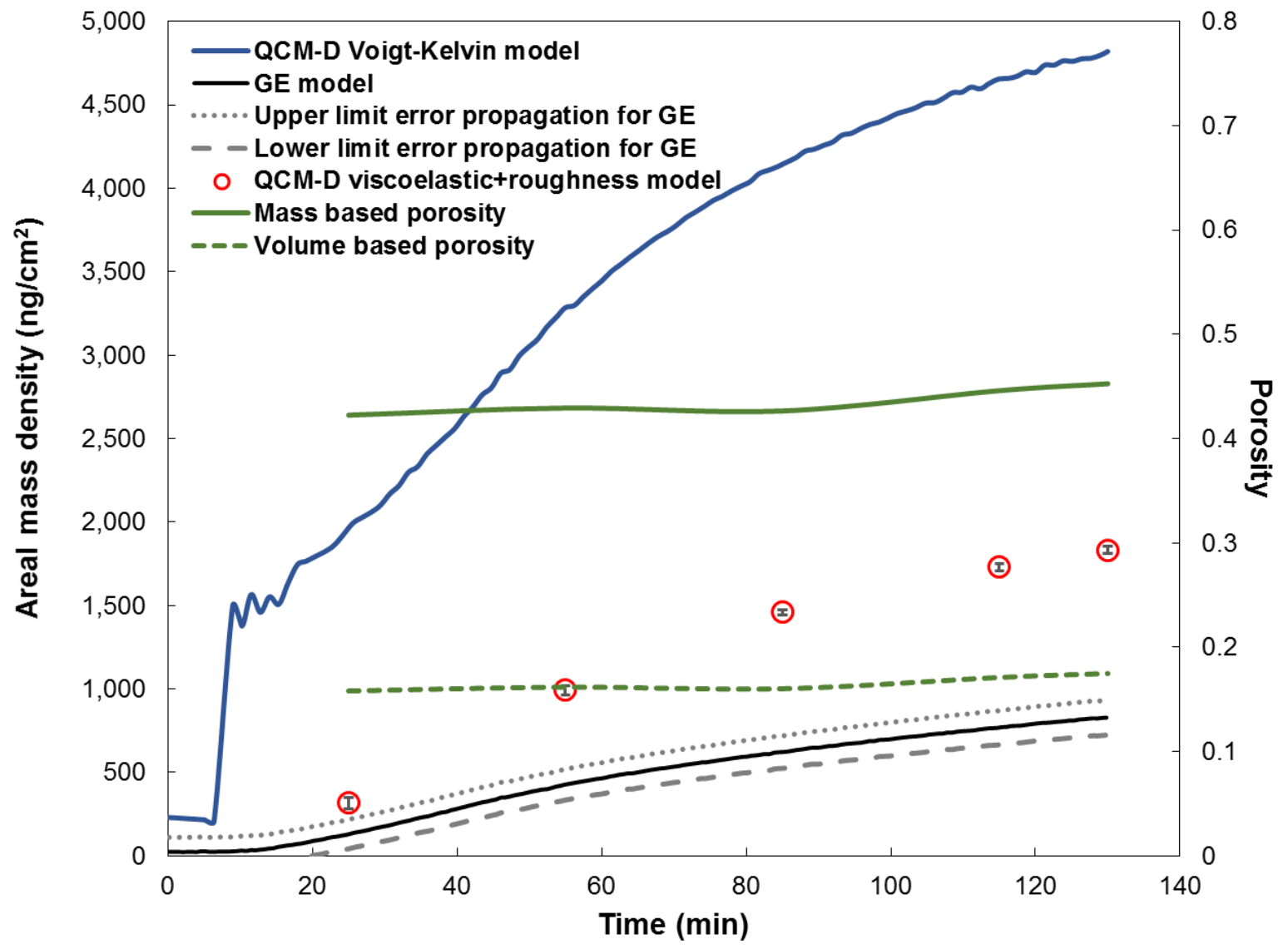

Figure 10: Comparison of areal mass density of attached $\mathrm{TiO}_{2} \mathrm{NP}$ between GE measurements, QCM-D Voigt-Kelvin model and QCM-D for the combined effect of surface roughness, and viscoelastic effect.

\section{5-Conslusions}

The deposition of $\mathrm{TiO}_{2} \mathrm{NP}$ on three-dimensional nanostructured SCTF surfaces was investigated using a combined method of QCM-D and GE. The SCTF surfaces with welldefined height and spacing served as models for rough surfaces. When $\mathrm{TiO}_{2} \mathrm{NP}$ deposited onto rough surfaces, QCM-D experiments revealed significantly higher frequency and dissipation shifts than on chemically similar but flat surfaces, which was attributed to contributions from 
both viscoelastic effects and surface roughness. A new model, combining both viscoelastic and surface roughness effects, was developed to interpret the QCM-D data. In this work we explicitly make use of the fact that functions $\Delta \mathrm{f}_{\mathrm{n}} / \mathrm{n}$ and $\Delta \mathrm{D}_{\mathrm{n}} / \mathrm{n}$ spread versus $\mathrm{n}$ during deposition. We use equations which are capable of reproducing the different $n$ dependencies that we have observed in the experiment. The observed spread is not random but systematic. We are now able to perform best-match model calculations using functions $\Delta \mathrm{f}_{\mathrm{n}} / \mathrm{n}$ and $\Delta \mathrm{D}_{\mathrm{n}} / \mathrm{n}$ and experimental data, and obtain model parameters such as areal mass density, viscoelastic properties of attached $\mathrm{TiO}_{2} \mathrm{NP}$, the vertical roughness length and permeability length. The model indicated that, as more particles attached to the surface, areal mass density parameter, as well as vertical roughness length parameter increased; the storage modulus parameter increased slightly, and the permeability length parameter decreased. Water adsorbed into nanoparticles or trapped between attached nanoparticles and inside the pores of SCTF greatly contribute to the frequency shifts.

In parallel to QCM-D, the areal mass density of $\mathrm{TiO}_{2} \mathrm{NP}$ obtained from independent GE measurements was about half of the QCM-D modeling results of combined surface roughness and viscoelastic effects, and one sixth of the Voigt-Kelvin QCM-D modeling approach. The porosity of attached $\mathrm{TiO}_{2} \mathrm{NP}$ layer, estimated by comparing the results obtained from the combined roughness and viscoelastic model for the QCM-D experiment, and the optical data analysis for the GE experiment, remained constant, which suggests a constant contribution of $\mathrm{TiO}_{2} \mathrm{NP}$ hydration over the course of experiment. It confirms that the newly developed QCM-D modeling approach successfully differentiated between nanoparticle deposition and water entrapment in rough areas, both of which contributed to frequency shifts.

\section{Acknowledgements:}

Support for this research was provided in part by funds from the Center for Nanohybrid 
Functional Materials (NSF-EPS-10004094) and NSF awards CBET- 1133528, CBET- 1521428.

We thank Thompson Delon for his help on some experiments. The research was performed in part in the Nebraska Nanoscale Facility: National Nanotechnology Coordinated Infrastructure and the Nebraska Center for Materials and Nanoscience, which are supported by the National Science Foundation under Award ECCS: 1542182, and the Nebraska Research Initiative.

\section{References}

[1] J. Fatisson, R.F. Domingos, K.J. Wilkinson, N. Tufenkji, Deposition of TiO2 nanoparticles onto silica measured using a Quartz Crystal Microbalance with Dissipation monitoring, Langmuir. 25 (2009) 6062-6069.

[2] P. Yi, K.L. Chen, Release kinetics of multiwalled carbon Nanotubes deposition on silica surfaces: Quartz Crystal Microbalance with Dissipation (QCM-D) measurements and modeling, Environ. Sci. Technol. 48 (2014) 4406-4413.

[3] P. Yi, K.L. Chen, Influence of solution chemistry on the release of multiwalled carbon nanotubes from silica surfaces, Environ. Sci. Technol. 47 (2013) 12211-12218.

[4] P. Yi, K.L. Chen, Influence of surface oxidation on the aggregation and deposition kinetics of multiwalled carbon nanotubes in monovalet and divalent electrolytes, Langmuir. 27 (2011) 3588-3599.

[5] B.J.R. Thio, D. Zhou, A.A. Keller, Influence of natural organic matter on the aggregation and deposition of titanium dioxide nanoparticles, J. Hazard. Mater. 189 (2011) 556-563.

[6] I. Chowdhury, M.C. Duch, N.D. Mansukhani, M.C. Hersam, D. Bouchard, Deposition and release of graphene oxide nanomaterials using a Quartz Crystal Microbalance, Environ. Sci. Technol. 48 (2013) 961-969.

[7] X. Liu, G. Chen, C. Su, Influence of Collector Surface Composition and Water Chemistry on the Deposition of Cerium Dioxide Nanoparticles: QCM-D and Column Experiment Approaches, Environ. Sci. Technol. 46 (2012) 6681-6688. doi:10.1021/es300883q.

[8] J. Fatisson, S. Ghoshal, N. Tufenkji, Deposition of carboxymethylcellulose-coated zerovalent Iron nanoparticles onto silica: Roles of solution chemistry and organic molecules, Langmuir. 26 (2010) 12832-12840. 
[9] G.B. Alcantara, L.G. Paterno, A.S. Afonso, R.C. Faria, M.A. Pereira-da-Silva, P.C. Morais, et al., Adsorption of cobalt ferrite nanoparticles within layer-by-layer films: a kinetic study carried out using quartz crystal microbalance, Phys. Chem. Chem. Phys. 13 (2011) 21233-21242.

[10] K.L. Chen, M. Elimelech, Interaction of fullerene (C60) nanoparticles with humic acid and alginate coated silica surfaces: measurements, mechanisms, and environmental implications, Environ. Sci. Technol. 42 (2008) 7607-7614.

[11] N. Saleh, K. Sirk, Y. Liu, T. Phenrat, B. Dufour, K. Matyjaszewski, et al., Surface modifications enhance nanoiron transport and NAPL targeting in saturated porous media, Environ. Eng. Sci. 24 (2007) 45-57.

[12] E. Tellechea, D. Johannsmann, N.F. Steinmetz, R.P. Richter, I. Reviakine, Modelindependent analysis of QCM data on colloidal particle adsorption, Langmuir. 25 (2009) 5177-5184.

[13] F.N. Dultsev, E.A. Kolosovsky, Quartz crystal microbalance as a sensing active element for rupture scanning within frequency band, Anal. Chim. Acta. 687 (2011) 75-81.

[14] X. Jiang, M. Tong, H. Li, K.Yang, Deposition kinetics of zinc oxide nanoparticles on natural organic matter coated silica surfaces, J. Colloid Interface Sci. 350 (2010) 427-434.

[15] A. Pomorska, K. Yliniemi, B.P. Wilson, D.Shchukin, D. Johannsmann, G. Grundmeier, QCM study of the adsorption of polyelectrolyte covered mesoporous $\mathrm{TiO} 2$ nanocontainers on SAM modified Au surfaces, J. Colloid Interface Sci. 362 (2011) 180-187.

[16] A.L.J. Olsson, I.R. Quevedo, D. He, M. Basnet, N. Tufenkji, Using the Quartz Crystal Microbalance with Dissipation Monitoring to Evaluate the Size of Nanoparticles Deposited on Surfaces, ACS Nano. 7 (2013) 7833-7843.

[17] C.P. McNew, E.J. LeBoeuf, The role of attached phase soil and sediment organic matter physicochemical properties on fullerene (nC60) attachment, Chemosphere. 139 (2015) 609-616.

[18] C.Y. Shen, B.G. Li, C. Wang, Y.F. Huang, Y. Jin, Surface roughness effect on deposition of nano- and micro-sized colloids in saturated columns at different solution ionic strengths, Vadose Zo. J. 10 (2011) 1071-1081.

[19] T.C.G. Kibbey, The configuration of water on rough natural surfaces: Implications for understanding air-water interfacial area, film thickness, and imaging resolution, Water Resour. Res. 49 (2013) 4765-4774.

[20] E.M. V. Hoek, G.K. Agarwal, Extended DLVO interactions between spherical particles and rough surfaces, J. Colloid Interface Sci. 298 (2006) 50-58. 
[21] X.F. Huang, S. Bhattacharjee, E.M. V. Hoek, Is surface roughness a "Scapegoat" or a primary factor when defining particle-substrate interactions?, Langmuir. 26 (2010) 25282537.

[22] D. Siegismund, A. Undisz, S. Germerodt, S. Schuster, M. Rettenmayr, Quantification of the interaction between biomaterial surfaces and bacteria by 3-D modeling, Acta Biomater. 10 (2014) 267-275.

[23] E.P. Ivanova, V.K. Truong, J.Y. Wang, C.C. Berndt, R.T. Jones, I.I. Yusuf, et al., Impact of nanoscale roughness of Titanium Thin Film surfaces on bacterial retention, Langmuir. 26 (2010) 1973-1982.

[24] G.K. Darbha, C. Fischer, J. Luetzenkirchen, T. Schafer, Site-specific retention of colloids at rough rock surfaces, Environ. Sci. Technol. 46 (2012) 9378-9387.

[25] L. Daikhin, E. Gileadi, G. Katz, V. Tsionsky, M. Urbakh, D. Zagidulin, Influence of roghness on the admittance of the Quartz Crystal Microbalance immersed in liquids, Anal. Chem. 74 (2002) 554-561.

[26] K. Nakata, A. Fujishima, TiO2 photocatalysis: Design and applications, J. PHOTOCH. PHOTOBIO. C. 13 (2012) 169-189.

[27] C.Y. Wang, C. Böttcher, D.W. Bahnemann, J.K. Dohrmann, In situ electron microscopy investigation of $\mathrm{Fe}$ (III)-doped $\mathrm{TiO} 2$ nanoparticles in an aqueous environment, J. Nanopart. Res. 6 (2004) 119-122.

[28] E.J. Zucker Massaro, K.M. Sanders, L.L. Degn, W.K. Boyes, Detection of TiO2 Nanoparticles in Cells by Flow Cytometry, Cytom. A. 77 (2010) 677-685.

[29] T. Kasputis, A.K. Pieper, K.B. Rodenhausen, D. Schmidt, D. Sekora, C. Rice, et al., Use of precisely sculptured thin film (STF) substrates with generalized ellipsometry to determine spatial distribution of adsorbed fibronectin to nanostructured columnar topographies and effect on cell adhesion, Acta Biomater. 18 (2015) 88-99.

[30] T. Kasputis, M. Koenig, D. Schmidt, D. Sekora, K.B. Rodenhausen, K.J. Eichhorn, et al., Slanted Columnar Thin Films Prepared by Glancing Angle Deposition Functionalized with Polyacrylic Acid Polymer Brushes, J. Phys. Chem. C. 117 (2013) 13971-13980.

[31] K.B. Rodenhausen, R.S. Davis, D. Sekora, D. Liang, A. Mock, R. Neupane, et al., The retention of liquid by columnar nanostructured surfaces during quartz crystal microbalance measurements and the effects of adsorption thereon, J. Colloid Interface Sci. 455 (2015) 226-235.

[32] T. Kasputis, M. Koenig, D. Schmidt, D. Sekora, K.B. Rodenhausen, K.J. Eichhorn, et al., Slanted Columnar Thin Films Prepared by Glancing Angle Deposition Functionalized 
with Polyacrylic Acid Polymer Brushes, J. Phys. Chem. C. 117 (2013) 13971-13980. doi:Doi 10.1021/Jp402055h.

[33] E. Bittrich, K.B. Rodenhausen, K.J. Eichhorn, T. Hofmann, M. Schubert, M. Stamm, et al., Protein adsorption on and swelling of polyelectrolyte brushes: A simultaneous ellipsometry-quartz crystal microbalance study, Biointerphases. 5 (2010) 1-9. doi:Doi 10.1116/1.3530841.

[34] K.B. Rodenhausen, T. Kasputis, A.K. Pannier, J.Y. Gerasimov, R.Y. Lai, M. Solinsky, et al., Combined optical and acoustical method for determination of thickness and porosity of transparent organic layers below the ultra-thin film limit, Rev. Sci. Instrum. 82 (2011). doi:Artn 103111 Doi 10.1063/1.3653880.

[35] K.B. Rodenhausen, D. Schmidt, T. Kasputis, A.K. Pannier, E. Schubert, M. Schubert, Generalized ellipsometry in-situ quantification of organic adsorbate attachment within slanted columnar thin films, Opt. Express. 20 (2012) 5419-5428. <Go to ISI $>/ / / 000301053200063$.

[36] K.B. Rodenhausen, D. Schmidt, C. Rice, T. Hofmann, E. Schubert, M. Schubert, Detection of organic attachment onto highly ordered three-dimensional nanostructure thin films by generalized ellipsometry and quartz crystal microbalance with dissipation techniques, in: K. Eichhorn (Ed.), Ellipsom. Funct. Org. Surfaces Film., Springer, Berlin, 2013.

[37] H.T.M. Phan, S. Bartelt-Hunt, K.B. Rodenhausen, M. Schubert, J.C. Bartz, Investigation of Bovine Serum Albumin (BSA) attachment onto self-assembled monolayers (SAMs) using combinatorial Quartz Crystal Microbalance with Dissipation (QCM-D) and Spectroscopic Ellipsometry (SE), PLoS One. 10 (2015) e0141282.

[38] K.B. Rodenhausen, T. Kasputis, A.K. Pannier, J.Y. Gerasimov, R.Y. Lai, M. Solinsky, et al., Combined optical and acoustical method for determination of thickness and porosity of transparent organic layers below the ultra-thin film limit, Rev. Sci. Instrum. 82 (2011) 103111.

[39] D. Schmidt, M. Schubert, Anisotropic Bruggeman effective medium approaches for slanted columnar thin films., J. Appl. Phys. 114 (2013) 083510.

[40] H. Tompkins, E.A. Irene, Handbook of ellipsometry, William Andrew, 2005.

[41] D. Schmidt, E. Schubert, M. Schubert, Optical properties of cobalt slanted columnar thin films passivated by atomic layer deposition, Appl. Phys. Lett. 100 (2012) 011912.

[42] M. Rodahl, F. Höök, A. Krozer, P. Brzezinski, Kasemo. B, Quartz crystal microbalance setup for frequency and Q-factor measurements in gaseous and liquid environments, Rev. Sci. Instrum. 66 (1995) 3924-3930. 
[43] I. Reviakine, D. Johannsmann, R.P. Ritcher, Hearing what you can see and visualizing what you hear: Interpreting Quartz Crystal Microbalance data from solvated interfaces, Anal. Chem. 83 (2011) 8838-8848.

[44] M. V. Voinova, M. Rodahl, M. Jonson, B. Kasemo, Viscoelastic acoustic response of layered polymer films at fluid-solid interfaces: continuum mechanics approach, Phys. Scr. 59 (1999) 391-396.

[45] D. Johannsmann, The Quartz Crystal Microbalance in Soft Matter Research: Fundamentals and Modeling (Soft and Biological Matter), Springer, 2015.

[46] J. Malmstrom, H. Agheli, P. Kingshott, D.S. Sutherland, Viscoelastic Modeling of Highly Hydrated Laminin Layers at Homogeneous and Nanostructured Surfaces: Quantification of Protein Layer Properties Using QCM-D and SPR, Langmuir. 23 (2007) 9760-9768.

[47] D. Johannsmann, Viscoelastic, mechanical, and dielectric measurements on complex samples with the quartz crystal microbalance, Phys. Chem. Chem. Phys. 10 (2008) 45164534 .

[48] A. Bund, M. Schneider, Characterization of the Viscoelasticity and the Surface Roughness of Electrochemically Prepared Conducting Polymer Films by Impedance Measurements at Quartz Crystals, J. Electrochem. Soc. 149 (2002) E331-E339.

[49] D. Johannsmann, I. Reviakine, E. Rojas, M. Gallego, Effect of sample heterogeneity on the interpretation of QCM(-D) data: Comparison of combined Quartz Crystal Microbalance/ Atomic Force Microscopy measurement with finite element method modeling, Anal. Chem. 80 (2008) 8891-8899.

[50] L. Daikhin, M. Urbakh, Effect of surface film structure on the quartz crystal microbalance response in liquids, Langmuir. 12 (1996) 6354-6360.

[51] D. Gu, S. Yalcin, H. Baumgart, S. Qian, O. Baysal, A. Beskok, Electrophoretic Light Scattering for Surface Zeta Potential Measurement of ALD Metal Oxide Films, ECS Trans. 33 (2010) 37-41.

[52] M. Elimelech, J. Gregory, X. Jia, R.A. Williams, Particle deposition and aggregation: measurement, modeling and simulation, Butterworth-Heinemann, Oxford, England, 1995.

[53] Z. Adamczyk, M. Nattich, J. Barbasz, Deposition of colloid particles at heterogeneous and patterned surfaces. Adv., Colloid Interface Sci. 147 (2009) 2-17.

[54] L. Suresh, J.Y. Walz, Direct measurement of the effect of surface roughness on the colloidal forces between a particle and flat plate., J. Colloid Interface Sci. 196 (1997) 177-190. 
[55] S. Bhattacharjee, C.H. Ko, M. Elimelech, DLVO interaction between rough surfaces., Langmuir. 14 (1998) 3365-3375.

[56] C. Jin, S.D. Normani, M.B. Emelko, Surface roughness impacts on granular media filtration at favorable deposition conditions: experiments and modeling, Environ. Sci. Technol. 49 (2015) 7879-7888.

[57] H. Tamai, Y. Nagai, T. Suzawa, Latex deposition on fibers VI. Deposition state and interaction energy, J. Colloid Interface Sci. 91 (1983) 464-471.

[58] R.B. Bai, X. Zhang, Polypyrrole-coated granules for humic acid removal, J. Colloid Interface Sci. 243 (2001) 52-60.

[59] I. US research Nanomaterils, No Title, (n.d.). http://www.us-nano.com/inc/sdetail/269.

[60] I. Carton, A.R. Brisson, R.P. Richter, Label-free detection of clustering of membranebound proteins, Anal. Chem. 82 (2010) 9275-9281.

[61] L.Macakova, E. Blomberg, P.M. Claesson, Effect of adsorbed layer surface roughness on the QCM-D Response: Focus on trapped water, Langmuir. (23AD) 12436-12444.

[62] K.B. Rodenhausen, M. Schubert, Virtual separation approach to study porous ultra-thin films by combined spectroscopic ellipsometry and quartz crystal microbalance methods, Thin Solid Films. 519 (2011) 2772-2776.

[63] K.B. Rodenhausen, B.A. Duensing, T. Kasputis, A.K. Pannier, T. Hofmann, M. Schubert, et al., In-situ monitoring of alkanethiol self-assembled monolayer chemisorption with combined spectroscopic ellipsometry and quartz crystal microbalance techniques, Thin Solid Films. 519 (2011) 2817-2820. 